\title{
Introduction to the $2^{\text {nd }}$ issue of World Nutrition for 2018
}

Some 60-70 years ago, we now know that the oil industry realized its products were going to cause global warming. In the 1950s, my father told me that during medical conferences, he saw doctors being offered free packs of cigarettes by companies which then advertised that 3 doctors out of 4 "preferred" their brand. In the 1960s and 70s, formula companies hired the most senior nurses in Asian and African countries and paid them to use their seniority to pressure more junior nurses into joining them in promoting infant formula. One formula company bragged in shareholder reports at that time that $95 \%$ of mothers who received a free sample of their brand in a hospital went on to buy that brand.

Skip ahead to the early 1990s. The government of China, eager to prevent the erosion of its breastfeeding culture, insisted that hospitals report increased breastfeeding rates every year; 3000 hospitals quickly became baby friendly. But within a decade that ancient breastfeeding culture was destroyed. The formula industry had realized what a gigantic new market it would soon become and began paying hospitals, baby friendly or not, to give away free samples. Baby friendly status gave you a plaque but didn't pay anything.

A few years ago, when I was a professor at a university in South Korea--where male alcohol consumption is three times as high as it is in the UK--alcohol companies advertised to college girls (typically shy and well knowing that they are on the bottom of the social ladder) that they will achieve instant popularity if they do shots with the boys.

Action has been and is being taken against all these industries. But we in public health nutrition are still the chumps of the activist world. Somehow the junk food industry has convinced too many of us and too many policymakers that, in effect, an entire generation of the human race mysteriously lost its "will power," stopped getting any exercise, and is itself entirely to blame for the horrific endemic of obesity and non-communicable diseases that is washing over the entire world like a caloric tsunami.

This issue of WN publishes a letter written and signed by the leadership of the World Public Health Nutrition Association and others around the world calling out WHO for its inability and unwillingness to tell the truth about the issues involved in its recent report "Time to Deliver". Oddly, WHO advises countries to shut out the tobacco industry from relevant policy making processes-but then suggests they invite the food industry in.

Two further articles explain in part how the global junk food industry has achieved its amazing coup against global public health. JP Dadich presents a case study of how the food industry works its magic (for owners and shareholders) and M Mialon et al present a case study of how the industry has worked against front of package nutritional labeling in France. They explain in detail the hidden, nefarious way in which the industry subverts even relatively minor public health initiatives like this. We nutritionists can be successful in promoting public health only if we understand and expose, and counteract exactly what Big Food does.

We hope our readers will share this issue of the journal, this information, and join us in acting. Tell your governments and WHO that enough is enough. Unhealthy food like sugary drinks should be taxed. And some way must be found to subsidize and encourage the production and consumption of healthy foods, 
especially fruits, vegetables, nuts and beans. Will power is not and never was the main problem. Giant companies with thousands of scientists paid to develop addicting foods and to promote them around the world are a large and likely the major part of the problem. Dealing with them head on is thus the most important part of the solution. No more Mr. Nice Guy Nutritionist.

This issue of the journal also contains a rare and fascinating detailed evaluation by $L$ Du et al of a project combining the two critical fields of agriculture and nutrition in a large-scale project in Bangladesh. They examine the extent to which farmer schools may have improved dietary diversity among women.

Two commentaries deal with the broader links between nutrition and health ( $R$ Keith on the importance of Alma Ata and the forthcoming Astana Conference) and between nutrition and political economics (a call to action from the People's Health Movement by D Sanders et al.).

Our previous issue had several inputs focusing on famine. In this issue our Deputy Editor George Kent provides his usual Good Question, this time asking some controversial questions about how to prevent famine. Responses are welcome!

Finally, we dedicate this issue to a friend, colleague, and strong supporter of both the World Public Health Nutrition Association and this journal, John Mason. Sadly, he passed away on August 28. As can be seen from the tributes published in this issue, he played a critical role for five decades in the field of public health nutrition and will be sorely missed. 